\title{
Who is being taught? Weaving academic spaces and teaching bodies
}

\author{
Rozmin Jaffer \\ Mount Royal University \\ rjaffer@mtroyal.ca
}

\begin{abstract}
The notion of embodiment, arising out of Body studies and complex ecological theories, situate the body as central to all social action, experience, learning, and research. Spatiality duly problematizes "space" and "place" suggesting that the sites which our bodies inhabit are culturally constructed and constructing. In light of the above, I show how the "teaching" body, as a particular kind of "institutional" body, is enacted, defined, viewed, and treated by others in specific sites. Furthermore, how is the teaching body--at once rendered racialized and gendered--inscribed, marked, bureaucratized, and regulated in institutional settings?
\end{abstract}

\section{Introduction}

I would like to respond to the above question by exploring various ways in which 'teaching' bodies enact and are enacted within specific sites in academia. I argue that postmodern conceptions of space are useful in imagining new possibilities for the relationship between subjectivities/identities of teaching bodies and the academic spaces they inhabit. Modernist conceptions of space and subjectivity have not enabled us to appreciate the complex relationship of the two concepts. Mainly, modernism has fixed both conceptions of space and subjectivity such that we view these as coherent, stable and unchanging. This view has paralyzed our ability to understand the dynamic and incoherent nature of both space and subjectivity. In modernist conceptions, two main opposing views of these concepts exist. First, that power works through ideologies to control and manipulate people such that they are rendered passive. Hence, people are manipulated by power that is held by specific individuals or groups, such as capitalism. The second view is that we have 'free will' and we can make choices that are independent of societal contexts. Thus, modernism acknowledges society's influence on our choices however this framework maintains that we can make decisions outside of these influences. Additionally, if we agree with the notion that people are passive and controlled by power, it is then difficult to realize agentic possibility. In these ways, such understandings of subjectivities and space are limited. Many social theorists have made good arguments in refuting these modernist conceptions of subjectivity (Spivak, 1990; Lather, 1999).

In modernist conceptions space has also been viewed as inert and stable. In turn, subjectivities/identities inhabit this stable inert space. This view of space renders unrecognizable the relationship of space and subjectivities. Postmodernism allows us to view space and subjectivity as fluid, changing and constantly in flux, thus allowing for new possibilities for the conceptions of space and subjectivities, and their relationships to each other. One such possibility is the emergence of 'sites of resistance' within 
postmodernist understandings of power relations as they inscribe subjectivities. Hence, techniques of power that discipline and oppress also produce sites of resistance for subjectivities. These 'sites of resistance', although not independent of cultural inscription, open up potential for agency. This is only one example of the various possibilities that exist when we employ a postmodernist lens. Specifically, postmodernist conceptions of space and subjectivities afford us new opportunities for understanding subjectivities/bodies of women of color who are educators in academic spaces. I am a woman of colour academic who is deeply invested in this relationship.

In the first part of this paper, I present a postmodernist understanding of space as discussed by geographers and feminists, followed by postmodern notions of subjectivities as bodies, where Foucault and feminists such as Grosz, Bartky, Teather, Butler and others, suggest that bodies should be viewed as inscriptive surfaces. The second part of the paper discusses specifically the way in which teaching bodies of women of color educators become inscribed by academic spaces. I discuss how space and bodies are mutually constitutive.

\section{Postmodern Spaces}

Massey attempts to formulate concepts of space and place in terms of social relations. Particular ways of thinking about space or place are tied up with specific constructions such as race, class and gender. Central to her theory is that space and time are integrally linked. Hence, space cannot be thought of as an absolute, independent dimension, but as constructed out of social relations (Massey, 1994). In this way, it is not that social phenomenon exists in space, but rather that social phenomenon and space are both constituted as social relations. Social relations are not still, but inherently dynamic; space, then, is also understood as dynamic. Massey expands on this notion:

The view, then, is of space-time as a configuration of social relations within which the specifically spatial may be conceived of as an inherently dynamic simultaneity. Moreover, since social relations are inevitably and everywhere imbued with power and meaning and symbolism, this view of the spatial is an ever-shifting social geometry of power and signification. (p. 3)

This way of conceptualizing the spatial inherently implies the existence in the lived world of a "simultaneous multiplicity of spaces: crosscutting, intersecting, aligning with one another, or existing in relations of paradox or antagonism" (ibid, p. 3). This is so because the social relations of space are experienced differently, and variously interpreted, by those holding different subject positions. 'The spatial', then, can be seen as constructed out of the multiplicity of social relations across all scales - from the global, to the national, through to the relations within town, settlement, household and workplace. Massey's is a view that considers the ever-shifting geometry of social/power relations where we see the multiplicities of space-time, a view of space that is the opposite of stasis or an immobilized surface. Politically, we encounter exclusivist claims to places such as nationalist, regionalist and localist. Each of these is an attempt to fix meaning to particular spaces, to enclose and endow these spaces with fixed identities, and to claim them for one's own. These understandings rest on particular views of place as bounded, as a site of authenticity, as singular, and unproblematic in its identity. 
However, spatial is thought of as the context of space-time of social interrelations at all scales. Moreover, one view of a place is a particular articulation of relations, a particular moment in networks of social relations and understandings. Importantly, this space includes relations that stretch beyond it, such as the global, which constitutes the local and outside as part of the inside (Massey, 1994). Identities of place are always unfixed, contested and multiple. The particular of any place, is in these terms, "constructed not by placing boundaries around it and defining its identity through counter position to the other which lies beyond, but precisely (in part) the specificity of the mix of links and interconnections to that 'beyond'. Places viewed this way are open and porous" (Massey, 1994, p. 5).

There have been many battles over the power to label space-time, to impose the meaning attributed to a place, for however long or short a time. Firstly, there are contests over the label/identity/boundary to be assigned. Secondly, there is an insistence on pointing out, and thus, challenging, the nature of that debate itself. Said gives an illustration of the latter:

With regard to the consensus on group or national identity, it is the intellectual's task to show how the group is not a natural or god-given entity but is a constructed, manufactured, even, in some cases, invented object, with a history of struggle and conquest behind it, that it is sometimes important to represent. (Said 1993)

It is this understanding of space and place with which postmodernists move forward to better understand the spatial and the identities that inhabit it. I bring forth a narrative of Himani Bannerji, a faculty member at York University. She presents us with an understanding of the multiplicities of space and identities: the way in which one is constructed and manufactured.

Bannerji (1991) speaks of the ways she understood herself in India and Britain. She recounts, "the white man left us, the states were ours but inscriptions and fossils of colonialism lay everywhere, though often unrecognizable as such because they were so effectively internalized" (1991, p. 80). This statement is laden with systems of ideas that inscribe her and others. She states, "they (the inscriptions of colonialism) were so effectively internalized". How were they effectively inscribed? What made these ideas her own? One of the ways in which authorship of colonial ideas was effectively constructed was by the employment of the grand narrative that the British culture was the 'right' way to be (Said, 1979). This grand narrative hailed that Britain was the best civilization and others should follow. What strategies regulated, disciplined and monitored the Indian woman in Bannerji's India? How were these ideas embedded in the cultural space such that they were perceived as 'the way things are'? Given that, inscription leads to both domination and resistance (Foucault, 1977). What were some of the spaces of resistance? Within this regime of truth, how are spaces produced for regulating and subverting the relations of power? How did the body become 'Indian' and 'woman' in order to effectively participate in the colonial grand narrative? Bannerji states that she went to an English school to learn the British culture and language. English literature was interpellated as the 'best' to Bannerji. Hence, her body was normalizedmeasured, catalogued, segmented and examined - through colonial discourse. Failure to produce self as pseudo-British was not just an error or a mistake, but rather a failure to be 'civilized' or 'human'; in which case, a body that wasn't pseudo-British did not count as 
human. Hence, Bannerji learnt to speak English and to incorporate as her own 'true' knowledge, Shakespeare and Dickens. Her body became produced by these knowledges. She demonstrates this by stating, " great literature or culture were universal, we learnt. They transcend space and history. English literature and language seemed ours by the same logic". It was this logic that made the English culture hers. Her body perceived this culture as hers and the actions that followed spoke that. How did she self-style? She spoke English, learnt about Shakespeare and Dickens. These figures became a part of her body, the textual fabric that constructed her identity/subjectivity. She states, so we never quite thought that 'our' Dickens... had a particular local home and a daily social belonging, but rather, Dickens belonged to her and her culture, her body/self - she/her body/self ultimately self-produced as pseudo-British. Her alienation from this 'universal culture' began, ironically enough, in England.

That 'our' Dickens might have looked at me in the streets of London, as others did, with thinly veiled hostility and not seen our common ground in the 'universality of a refined literary sensibility'--became apparent to me many years ago in Porto Bello Road.... though I did not know it then, I was being produced as 'the other', as 'different', but not neutrally different, not just as a cultural variation on the theme 'human', but as 'different and inferior'. (p. 98)

In this narrative, Bannerji illustrates the spatial within which inhabits complex social relations. These relations manufacture and even invent her as 'Other'.

This narrative leads towards a better appreciation of the multiplicity of power relations within social space. In this way, space can better demonstrate the myriad of connections that are constantly occurring within social practices. Bannerji's narrative demonstrates that space is constantly changing and inscribing her body. The ways in which these inscriptions occur have also been debated in the literature. Jameson argues that,

A new kind of spatial imagination capable of confronting the past in a new way and reading its less tangible secrets off the template of its spatial structures body, cosmos, city as all those marked the more intangible organization of cultural and libidinal economies and linguistic forms. (Jameson 1991, p. 364) Jameson suggests that space may be a template from which the intangible organization of social practices can be read and better understood. This intangible organization is embedded in Bannerji's illustration, where she is required to perform and speak in a particular way.

\section{Bodies as Inscriptive Surfaces}

Many theorists suggest that we can ascertain the "hidden human geography of power" by understanding the special specificity of the various subject positions they take on in social relations (Keith \& Pile, 1993, p. 4). However, Soja's conceptual schema counters this and states "that even the dynamic understanding of the situation is too solid: space in not an innocent backdrop to (subject) position, it is itself filled with politics and ideology" (Keith \& Pile, 1993, p. 4). Soja further expands,

We must be insistently aware of how space can be made to hide consequences from us, how relations of power and discipline are inscribed into the apparently 
innocent spatiality of social life, how human geographies become filled with politics and ideology. (Soja, 1989, p. 6)

He argues that space has been misrecognized by contemporary social theory.

"What is lost from view are the deeper social origins of spatiality, its problematic production and reproduction, its contextualization of politics, power and ideology" (Soja, 1989, p. 125). In this contextualization, "human geographies" or bodies become filled with ideology. Hence, space and bodies are mutually constitutive.

Grosz, a feminist scholar, suggests an understanding of body that highlights this as an inscriptive surface. She states,

By body I understand a concrete, material, animate organization of flesh, organs, nerves, muscles, and skeletal structure which are given a unit, cohesiveness, and organization only through their psychical and social inscription as the surface and raw materials of an integrated and cohesive totality... The body becomes a human body, a body which coincides with the 'shape' and space of a psyche, a body whose epidermic surface bounds a psychical unity, a body which thereby defines the limits of experience and subjectivity, in psychoanalytic terms through the intervention of the (m)other, and ultimately, the Other or Symbolic order (language and rule-governed social order). (Grosz, 1992, p. 243)

It is clear that the body is more than flesh and bones. Indeed, space and place are perceived, lived and produced by the means of the body. Although our bodies occupy space, they are also fluid places in their own right. Pile suggests that the 'space' of our body is encoded with "maps of desire, disgust, pleasure, pain, loathing, love" (Pile 1996, p. 209).

Pillow (2000) refers to the physicality of teen pregnant bodies and the various ways in which 'space' contains marks and regulates these bodies. She suggests that our bodies speak, without talking, because they become encoded with and as signs, such that they speak social codes, laws, ideals and norms that become incarnated (Pillow, 2000). "These social codes we live by are complex and conditional and are further coded, often without acknowledgment, by issues of gender, race, class, physical characteristics, and sexual identity" (Pillow, 2000, p. 201).

Foucault is helpful in understanding how bodies become socially coded. He interprets Nietzsche on the way in which history affects bodies and the interface between bodies and knowledges. In this way knowledge both extracts from the body and in turn helps to form the body. Foucault states,

The body — and everything it touches: diet, climate, and soil — is the domain of [descent: the object of genealogical investigation]. The body manifests the stigmata of past experiences and also gives rise to desires, failings and errors...

The body is an inscribed surface of events (traced by language and dissolved by ideas), the locus of a dissociated Self (adopting the illusion of a substantial unity), and a volume in perpetual disintegration. Genealogy, as an analysis of descent, is thus situated within the articulation of the body and history. Its task is to expose a body totally imprinted by history and the processes of history's destruction of the body. (1977, p. 148)

For Foucault, power-knowledges operate through the body. In today's society, under the forms of disciplinary normalization, power utilizes, produces the subject's desires and pleasures to create knowledges, truths, which may provide more refined, improved, and 
efficient techniques for the surveillance and control of bodies. The body is the site at which the play of powers, knowledges, and resistances is being worked out.

Knowledge is understood by Foucault to be that which is socially recognized as knowledge. Hence, knowledge and truth are what a particular culture values as true, what functions as true. Knowledge is a major instrument and technique of power. Knowledge is made possible through regimes of power. Power in turn, is transformed, realigned with the transformations in the order and functioning of knowledges. Power and knowledge actively feed each other; they are mutually conditioning. Moreover, the body is the site of power relations. Power is the condition under which truth can be distinguished from falsehood (Grosz, 1994). "As legitimized and sanctioned knowledge, discourses are then able to feed back into the regimes of power (through the body) which made them possible and to enable power to be operated in more subtle or systematic, more economical or vigilant, forms" (ibid, p. 148). The relationship of the body and power is expanded on by Foucault,

The body is molded by a great many distinct regimes; it is broken down by the rhythms of work, rest and holidays; it is positioned by food or values, through eating habits or moral laws; it constructs resistances... Nothing in man-not even his body - is sufficiently stable to serve as a basis of self-recognition or for understanding other men (1997, p. 153).

Given that nothing is stable in bodies, our understanding of self and others can therefore be partial at best.

Furthermore, the relations of power produce the body through the use of distinct 'techniques', such as feeding, training, supervision, and education of children in any given culture. These techniques harness the energies for subversion that power itself has constructed, such as regimes of order and control in modern disciplinary societies. There is a need to create 'docile', obedient subjects whose bodies and movements are parallel with the efficiency of a machine, or to create a body whose desire is to confess its innermost subjectivity and sexuality to institutionally sanctioned authorities (Grosz 1994). The body is the site for power's operations. Power produces the body with particular characteristics, skills and attributes. Power produces the internal etching of the interiority or 'soul' of the body-subject (Grosz, 1994). "The soul (or interiority) is the effect and instrument of a political anatomy; the soul is the prison of the body" (Foucault, 1977, p.30). Power does not control the subject through the systems of ideas or ideologies or through coercive force; rather, power surveys, supervises, observes, and measures the body's behavior and interactions with others in order to produce knowledges. It punishes those resistant to its rules and forms. The way in which power does that is to create new modes of control, new forms of observation and thus new forms of power-knowledges.

Consequently, new sites of resistance are formed. For Foucault, power deploys discourses on and over bodies, in this way, establishing knowledges as the representatives of truth of those bodies and their pleasures. Power both exploits discourse and makes it possible. Discourse and power intermesh with bodies, with the lives and behavior of individuals, to constitute them as particular bodies. "Power is the condition of possibility of these true discourses, the motivating force behind their profusion and the energy which inscribes them on bodies..." (Grosz, 1994, p. 150). Foucault's description of the penal system and the ways in which bodies were once tortured in public illustrates these as 
modes of social control for particular social institutions. These social institutions include the family, army, school, work environments and so on. Foucault labels the disciplinary power over life as biopower, the power to regulate the minute details of daily life in both the individual and populations (Grosz, 1994). I will later explore how the concept of biopower plays out in academic spaces, inscribing the teaching bodies.

The body and gesture are inseparable. The body makes statements, either involuntary or voluntary. Teather suggests, "it is through the body's sensory organ that we perceive the qualities of space; through our cultural baggage we assess space; through a combination of creativity and motor skills we adapt and design space" (1999, p. 7). An example of this may be the educator who adheres to critical pedagogy. It is through our cultural baggage that the educator assesses space as 'critical pedagogy', hence, adapting and designing classroom spaces to emulate principles of this theory. In a similar manner, she is designing other spaces such as, family, social groups etc. to reflect principles of this theory. Hence, it is through this cultural baggage of this theory that we adapt our bodies to perform in particular ways. For instance, this educator would perform so that her theoretical goals of democracy are accentuated in the classroom. This may be done by sharing power in the classroom and seating students in a circle.

Whereas psychoanalysis and phenomenology focus on the body as it is experienced, rendered meaningful, enmeshed in systems of signification, Nietzsche and Foucault focus on the body as a social object. Grosz (1994) reads Foucault through a feminist lens and offers the body,

As a text to be marked, traced written upon by various regimes of institutional (discursive and non-discursive) power, as a series of linkages (or possible activities which form superficial or provisional connections with other objects and processes, and as a receptive surface on which the body's boundaries and various parts...are constituted, always in conjunction and through linkages with other surfaces and planes. (p. 116)

Foucault (1977), drawing from Nietzsche, views the body as a field of politics. Foucault examines institutions, both material (families, schools, prisons, etc.) and discursive (the disciplines and other formalized knowledges in the social sciences) that shape the body, which is the situated embodied structure of subjectivity. Further, Foucault suggests that the process of getting to know and the process of getting to control the embodied selfbeing are one and the same thing. He demonstrates that the 'truth-effects' produced about the embodied subject are both correctional, normative, and positive, that is productive of knowledge.

As mentioned earlier, power is viewed as highly relational and dispersed within the microphysics of the most detailed techniques of knowledge and control. Additionally, Foucault suggests that the body is the object and the target of power: a "body that is manipulated, shaped, trained, which obeys, responds, becomes skilful, and increases its forces" (Foucault, 1977, p. 26). He highlights the materiality of the corporeal subject, meant as a site of control but also of strategies of resistance. It is important to note here that in the same moment as particular bodies are controlled, they are presented with the means of resistance. The body is marked more or less permanently and impermeably. Inscriptions occur both violently and in more subtle forms. Violence is demonstrable in social institutions of correction and training, prisons, juvenile homes, hospitals, psychiatric institutions, keeping the body confined, constrained, supervised and 
regimented, these being implemented by handcuffs, shock therapy, the straitjacket, regime of drugs, solitary confinement and deprivation of mobility, to name a few (Grosz 1994).

More subtle, but no less coercive, are the inscriptions of cultural values, norms, and commitments "into the morphology and the categorization of the body into socially significant groups - male and female, black and white, and so on" (Grosz, 1994, p. 143). Although the body is involuntarily marked, it is also incised through compliance such as, life-styles, habits, and behaviours. Make-up, stilettos, bras, hair sprays, clothing and underclothing mark women's bodies in ways that body building, sports, professionally trained mark men's bodies. None of these corporeal inscriptions are natural or ahistorical. Indeed, through these inscriptions, bodies are made amenable "to the prevailing exigencies of power" (ibid, p. 142). Grosz suggests that "culturally specific grids of power, regulation, and force (are) conditions that provide techniques for the formation of particular bodies" (p. 142). It is important to note that these procedures of inscription do not simply adorn or add to the biologically derived body, but rather they help constitute the "very biological organization of the subject — the subject's height, weight, coloring, even eye color are constituted as such by a constitutive interweaving of genetic and environmental factors" (ibid, p.142). Hence, every body is marked by its history and specificity.

Furthermore, Foucault stresses that the various procedures for inscribing bodies do not just occur from the outside. Moreover, they do not function coercively, but are sought out. Foucault analyzes the ancient Greeks for their techniques of self-regulation, the ways in which individuals valued their conduct and performed their duties. He describes the ethical relationship one has to self as, "the practices which led individuals to focus their attention on themselves, to decipher, recognize, and acknowledge... a certain relationship that allows them to discover, in desire, the truth of that being" $(1985$, p. 5). Such practices are undertaken voluntarily and usually require the active compliance of the subject. Hence, the notion of women's bodybuilding is not just imposed from without, but is actively undertaken, such that we are all compliant. Only then are these procedures effective. Foucault would call these "techniques of self-production". Bartky (1988) illustrates techniques of self-production within the discourse of women's bodybuilding,

The woman who checks her makeup half a dozen times a day to see if her foundation has caked or her mascara has run, who worries that the wind or the rain may spoil her hairdo, who looks frequently to see if her stockings have bagged at the ankle or who, feeling fat, monitors everything she eats, has become, as surely as the inmate of the Panopticon, a self policing subject, a self committed to a relentless self-surveillance. This self-surveillance is a form of obedience to patriarchy. (p. 81)

Arguably, we are all caught up in the process of self-production and self-observation. This process intertwines us within various networks of power. In this way, we are never rendered as passive.

McWilliam (2000) illustrates ways in which the academic's body is selfproduced. She states,

The body of the academic, like that of any other modern citizen, has been normalized--measured, catalogued, segmented, and examined--through 
disciplinary discourses. Such practices work to eliminate risk inasmuch as risk means the real possibility of mistake, error, and failure. This is not simply failure to complete a particular task to an acceptable standard, but...failure to produce oneself as a reasoning, reasonable citizen. (p.169)

Failure to produce oneself as a reasoning, rational 'citizen' becomes the most critical failure for the body of the academic. Hence, it is not simply to complete a particular task as a 'good teacher' might, but whether one sees self as a 'good citizen', where good is tied with particular forms of embodied performances. These bodies of the academic perform 'good' in a variety of ways: by joining research committees, acquiring tenure, publishing articles and participating in civil society possibly through research projects. Attitudes, gestures and the 'dress' of the teacher must adhere to the performances of 'good'. Hence, the educator must wear appropriate formal clothing, must be selfcontained in her gestures, and must articulate in a particular way. All these make her recognizable by academic standards of normalization. She must appear 'normal' in her appearance, gestures and attitudes.

Butler (1993) dismantles Foucault's notion that bodies are entirely social texts. She explores the nature/culture interface through the question of corporeality. Butler engages the hierarchy of the nature/culture opposition that has informed the sexualizing and racializing agendas in many different forms throughout the history of western thought. Her work focuses on the notion of bodily inscriptions. She suggests that the assertion of the body as culturally constructed is a paradox. She explores the ways in which (what she calls) the scenography or topography of this construction might be said to matter. Butler states,

Surely bodies live and die; eat and sleep; feel pain, pleasure; endure illness and violence; and these "facts," one might skeptically proclaim, cannot be dismissed as mere construction. Surely there must be some kind of necessity that accompanies these primary and irrefutable experiences. (1993, p. ix) Butler claims that the stuff of human existence provides a limiting inscriptive surface. The materiality of the body limits what is possible and impossible given the "facts" of human condition. Foucault, on the other hand, rarely takes into account the "facts" or materiality of the human being. Instead, he refers to a generic body that is a "given". In fact, he does not differentiate between a man's body and a woman's body; rather, he views the man's body as the 'given' condition. Butler interrogates Foucault's notion and makes the politics of the gendered body more explicit. Butler suggests that although there exists a materiality of the body, we don't have access to a pure materiality outside or before language. Hence, there is no access to a pure materiality of bodily life that is separate from language. Butler clarifies her opinion and claims, "it is not the case that everything, including materiality is always already language" (1993, p. 68). This is the paradox of materiality and language. Cornell echoes Butler's point that matter and ideas are absolutely separate; however, this does not mean that they do not have intimate proximity or overlap, but still retain their borders. This can be viewed as a Venn diagram, wherein "two recognizably different spheres are nevertheless involved in a mutual and constitutive relationship that compromises their integrity" (Kirby, 1997, p. 103). In this way, the ideal domain is mediated by language and the domain of matter is unintelligible.

It is only through language that the truth of the body's 'facts' is understood. Butler suggests that even if we can't access "outside language" that is unmediated by 
language, this does not mean that we try to refrain from speaking of this outside. Furthermore, internal to discourse is the production of exteriority or outside discourse. However, this is not to deny, or presume to exclude, this materiality, but to analyze the "process of materialization that stabilizes over time to produce the effect of boundary, fixity, and surface we call matter" (1993, p. 9). Butler is cautioning us against this process of materialization that fixes identities and subjectivities. In the next section, I will explore how these understandings enable us to imagine new possibilities for the relationship of academic spaces and subjectivities/bodies of women of color educators.

\section{Bodies in Academic Spaces}

Some educational theorists have described pedagogy as a "form of inscription, of body writing and mapping" (Schaafsma, 1998, p. 261). Bodies are usually not discussed as part of pedagogy. In fact, the body has often been negated in the classroom. Spelman explains this,

The descriptions and analyses of bodies that [have been] provided lack reflexivity - they fail to account for the bodily practices of the theorists, and they also perpetuate fear of speaking/dealing with the body, a tradition that Spelman calls "somatophobia in feminist theory" (Spelman 1988, p. 179).

Current educational theorizing marginalizes the place of emotions, the irrational and the body (Orner, 1998). Desire, fantasy and play of the unconscious are absent from the educational discourse or rendered politically insignificant. Ideas are often equated with cognition as a more rational intellectual encounter with pedagogical texts. What is unspoken in education is the emotional, the fear, and the guilt that accompanies ideas. Hence, particular ways in which bodies are invested in learning are rendered unintelligible. Orner states, "teaching and learning, at least in part, require the uncovering and recovering of our own and students' implication, interests and investments in the knowledge being forged" (Orner 1998, p. 279).

I am drawn to McWilliam's (2000) work, since it presents new imaginings of the relationship of the bodies of women of color educators and academic spaces. She suggests that the ways we have come to think and write about the teaching body renders certain 'normal' bodily processes unspeakable. Although we may know that all premenopausal women must spend approximately one quarter of their teaching time menstruating, this is not something that will be spoken of when discussing teacher quality and professional development (McWilliam, 2000). Bell Hooks gives an account of her days as a beginning teacher. She states,

When I first became a teacher and needed to use the restroom in the middle of the class, I had no clue as to what my elders did in such situations. No one talked about the body in relation to teaching. What did one do with the body in the classroom? Trying to remember the bodies of my professors, I find myself unable to recall them. I hear voices, remember fragmented details, but very few whole bodies. (Hooks, 1994, p. 192)

I would suggest that by attempting to erase the body in the classroom, we demonstrate that passion has no place in the classroom. I concur with Hooks that the classroom is the 
site of only particular performances, such that we forget feelings and passions, which must be recovered in some other space, such as in the bathroom (Hooks, 1994).

Hooks' own questioning of what should she do with her body in class demonstrates that in one way she is reinforcing the 'norm' that our bodily processes are separate and outside of our cognitive processes. However, in another reading, Hooks is disrupting this same norm. She does this by bringing her body into the pedagogical discourse. If we take this example to the extreme, we may be able to appreciate the techniques of power that discipline educators in the classroom. If she lost control of her bladder in class, hooks would be disciplined in the academy in a variety of ways. She would lose authority with her students, she may not be promoted in the academy and/or she may lose the respect of her colleagues. All of these disciplining strategies inscribe, regulate, beauracratize, and monitor her 'body' to perform in particular ways in the academic space.

McWilliam relates another example of bodies being inscribed in academic spaces. A woman faculty member is talking to some colleagues before a meeting and laughs heartily, at which time, a male colleague asks her to laugh more quietly. Feminists would suggest that the male colleague was once again attempting to oppress the woman educator. Another reading of this scenario suggests that the male colleague was actually helping the woman colleague by reinforcing and monitoring proper 'professional' performance in the academic space (McWilliam, 2000). Moreover, bodies are taught to monitor self to perform in academic spaces. The institutional body of the academy disciplines, punishes and rewards the teaching bodies depending on their performances. Bodies are taught through a variety of narratives of "good teacher". This is one example of how disciplining spaces of surveillance and regulation are rampant. Going back to the woman faculty member, she can lose respect from her colleagues and employers, not to mention her students, if she continues to laugh in a hearty, loud manner. She may not appear reasonable to others in the academic space. Hence, the containment of her bodily actions, such as laughter, must be maintained in the academic space. This resonates with narratives of bodies that are either contained or erased in the classroom.

Foucault states that there is scarcely a society without its major narratives which are recounted, repeated and varied; formulae texts, and ritualized sets of discourses which are recited in well defined circumstances. Stories that we tell in schools deploy complex disciplinary technologies. These storytellers make sense of their own construction in educational contexts, discourses, norms and practices. How are 'girls', 'boys ', 'women of color', 'marginalized' formed? How do they become their own gender or race overseer? In such a way, we are observing, judging, and disciplining every aspect of ourselves. These formulae texts or ritualized discourses occur in academic spaces that repeatedly inscribe and mark the educator. In this way, narrations become 'facts'. As Bannerji states, they become 'the way things are'. Consequently, teaching bodies become the authors and protectors of these 'facts'.

\section{Bodies of 'women of color' Educators}

Many theorists agree that the dominant discourses in academia are Europeancentered (Hall 1996; Ng 1993; Bannerji 1991; Hooks 1994). Consequently, these dominant discourses produce bodies as 'woman' or 'woman of color'. It is in these 
pedagogical contexts that I would like to locate the teaching bodies of 'women of color'. Bannerji, in her narrative, describes the way in which space and place produce her body/subjectivity, together with the alienation and belonging she feels in various spaces in India and Britain. Similarly, Simmonds draws attention to the way in which her body responds to being 'Othered' in academic spaces:

The world that I inhabit as an academic, is a white world...in this white world the question becomes: What relationship can a Black woman establish between being a sociologist and being a person? ...In this white world I am a fresh water fish that swims in seawater. I feel the weight of the water...on my body. (Simmonds, 1997, p. 226-227)

Bannerji suggests that particular textual strategies in academic spaces often develop into grotesque forms of self-alienation. These strategies arise from the way knowledge is produced as grand narratives that are universal or 'ways of seeing' society. She expands on the way these knowledges are produced, "It actually draws on and systematizes, an often uncritical, cultural 'common sense' in everyday practices and invests them with the status of knowledge (as social facts, norms, etc.) as well as knowledge-creating procedures (theories and methods)" (Bannerji, 1991, p. 94). Consequently, particular knowledge is produced as 'common-sense' knowledge.

Hence, this knowledge is viewed as universal and unproblematic. This textual strategy of 'common sense' knowledge alienates teaching bodies that are inscribed by other knowledges. 'Common sense' knowledge can exclude embodied knowledges of women, women of color, aboriginal peoples, disabled individuals or gays and lesbians, to name a few. Within academic spaces where 'common sense' knowledge is viewed as the standard, bodies that have been inscribed by opposing knowledges can become alienated, excluded and generally disciplined for not performing the 'common sense' norms. These bodies can easily become less respected by students who may see them as not being 'reasonable' or 'good' teachers. Moreover, these bodies may not gain publication in established academic journals. They may appear 'not rigorous' or 'unreasonable' to their colleagues.

I have described a variety of ways in which educators are disciplined to perform particular norms in academic spaces. I draw on Brook's work to describe how 'common sense' knowledge of gendered and racialized bodies can occur in academic spaces. Although Brook only discusses teaching bodies as gendered, I nevertheless wish to employ her conceptions to better understand the way in which bodies are rendered both racialized and gendered. She states that "the social body of the academy is not, as it might seem, a neutral figure, but rather that of the "straight white male"' (Brook, 2000, p. 184). I would further suggest that the "straight white male" is constructed as a neutral, generic figure, such that, when women academics deliver lectures, they fracture this generic position. Consequently, the woman educator receives ambivalence from her students. Wise illustrates this,

Typically I experience students as having simultaneously high expectations of me and little respect for me...Elitism, here, is something that students have striven for, and to arrive at university only to find that your "own kind" are there before you in positions of authority is an extreme disappointment. How much more 
gratifying to find a world that is different and elitist, but one that you too can now join. (Wise, 1997, p. 127)

Wise suggests that the desire for these mature aged female students in her class to be "straight white male" interrupts the positive representation of the lecturer as a model of success. It is precisely this familiarity of her physical body and their reading of its history that de-authorizes her, and creates skepticism towards her performance as an academic (Brook, 2000). It appears as though no matter how hard she repeats performances of "Academic", for these students, it will always be recognized as a performance, "a kind of a drag act" (Brook, 2000, p. 184). Hence, women educators are not perceived as 'real' teachers, but rather those who read from scripts generated by the 'straight white male'. Postmodernism suggests that all we have are scripts and that 'real' is a constructed notion.

In a similar way to Brook, Moira Gatens (1991) explores how gendered norms have been produced and reproduced in particular Western contexts within the body politic. I argue that racialized norms have been produced in a comparable way. One of the key social constructions that have reinscribed gendered and racialized relations in the 'political body' is that of the 'invisible' woman, woman of color, people of color, and so on. In constructing the body politic, Hobbes suggests an imaginary or 'artificial' man that must be conjured to protect the 'real' man. Hobbes views the body politic as the unified body. Thus, there is one body, one reason, and one ethic: that of the 'straight white male'. It is important to note that the 'invisible' others are not viewed as agents and thus not represented by this artificial man, and by extension the body politic. A possible reason may be that the artificial man incorporates, and so controls and regulates, bodies of women and people of color in a manner which does not undermine his claim (of 'man' being sovereign) since the contributions of 'man' are neither acknowledged nor visible. Second, since he can maintain this apparent unity through incorporation, he is not required to acknowledge difference (Gatens, 1991). In this way, difference can be denied and the unitary nature of the political body strengthened. Any 'others' become so invisible from this political body that if they even attempt to speak from the political body, about the political body, their speech is not recognized as human speech (Gatens, 1991). For example, when Mary Wollstonecraft addresses the issues of women's political rights, Walpole calls her a 'hyena in petticoats'. The strategy of reducing the woman to her sex, or people of color to their race, has occurred in many societal practices through the centuries. This textual strategy, among others, inscribes and regulates performances of those 'others' to act and perform in a particular manner. A woman's gestures, attitudes and beliefs become inscribed by these social spaces. Appropriate and inappropriate behaviour for these 'others' become coded as such within these spaces.

Similarly, academic spaces are coded spaces where bodies/subjectivities are produced (by society and self) to fit social norms or standards. The body politic described above is the broader context within which 'teaching' bodies that are 'women of color' are inscribed, marked, beauracratized and regulated in the academy. It is here that grand narratives or 'facts' held about knowledge, power and self are inscribed and reinscribed on the teaching body. Through ritualistic gestures of the body, both the political body and the teaching body are reminded of goals, aspirations and gestures that must be adhered to. However, it is crucial to note that, along with disciplining bodies, 'sites of resistance' are also produced by these same inscriptions. These sites of resistance are of great value in 
fracturing and rupturing particular grand narratives that exclude women and women of color in academic spaces. 'Sites of resistance' are important to explore since they enable us to imagine different possibilities (than the ones discussed above) for the relationship of academic spaces and teaching bodies. Hence, these sites of resistance afford us different possibilities for the relationship of women of color and the body politic.

\section{Rupturing Bodies in Academic Spaces}

It is my thesis that particular bodies rupture the current body politics that inhabit academic spaces in a number of ways. Bodies of women and people of color, by the sheer fact that they don't belong there, subvert and interrupt the unitary nature of the 'artificial man' of the political body. As gendered and racialized bodies enter academic spaces, they rupture these spaces by the 'difference' their bodies inscribe. In this way, subtle subversive acts are performed continually in academic spaces. Alison Bartlett highlights the way in which female teachers are an unruly and subversive materiality in a classroom. She states,

A friend of mine tells me that when she was teaching and suddenly thought of her nine-month-old baby, her breast milk would sometimes leak visibly onto her professional lecturer's blouse. Can this be possible? Do teachers' breasts leak and their wombs menstruate? What else might women's bodies entail, and how does this affect their pedagogical positions? (1998, p. 87)

McWilliam (2000) suggests, "Feminist documentations of disorderly, leaky, and malformed pedagogical bodies can work as a redeployment or counter production of culture and knowledge about teaching" (p. 173), since the 'disorderliness' would challenge particular professional standards that we adhere to in higher education. In this way, subversive acts can be a productive way of producing different knowledges, such as narratives that oppose 'common sense' accounts of institutionalized academic spaces.

Another example of rupturing bodies is the pregnant female body. This body further confounds and conflates our codes and norms. "The significance of the maternal body differs from the public body in that it is the site of the reproduction of the social body" (Diprose, 1994, p.25). Pregnancy interrupts accepted assumptions of the body and self. It confounds our notions of where our body ends and another begins. It interrupts the notion of a single unitary self (Pillow, 2000). The body is not as contained and predictable during pregnancy as norms of society would dictate.

Mary Russo's (1994) description of grotesque bodies within carnivalesque gives us another site for rupturing bodies. In the mainstream discourse carnivalesque allows "a redeployment or counter production of culture, knowledge and pleasure" (p. 62). She states, it is this "freakish performative pedagogy" that refuses to become normal (p. 8). Russo states that it is the materiality of the body that is the site of the carnivalesque. The material body is not, however, the "classical body" of modernity, "transcendent and monumental, closed, static, self-contained, symmetrical and sleek" (p. 8). Rather, it is the 'grotesque body' of the carnival, one that is "open, protruding, irregular, secreting, multiple and changing" (p. 8). The carnival body can be viewed as women's bodies or bodies of women of color in academic spaces. Women of color educators can be viewed as the 'grotesque body' of the carnival. The more their performances as academics resist 
norms of academic spaces, the more open, protruding and grotesque they become. It is this body that can be most useful in redeploying culture and knowledge about teaching, such that academic spaces may be reinscribed by these grotesque, leaky bodies. It is crucial to note that these bodies exceed the norm in a way that involves serious risk (Russo, 1994). This is a risk of not being accepted and respected in academic spaces. For example, a woman of color academic who calls herself a poststructuralist feminist could be said to have become an uncontrolled, disorderly body that ruptures the present academic space. However, as she does this (consciously and unconsciously), she resignifies, re-inscribes this same space. The way in which she ruptures particular grand narratives may be by dressing in a flamboyant manner, referring to bodily functions in the classroom, laughing out loud, having students sit on the floor and meditate before class, and finally introducing material whose source is constructed as 'non-academic'. In these ways and more, she will re-inscribe the academic spaces she inhabits. She will not be in control of the particular re-inscription, however her body will be part of a particular moment where change occurred. All of this of course comes with serious risks of being seen as not human or uncivilized.

\section{Conclusion}

This paper has explored various ways in which teaching bodies become inscribed, marked, regulated and disciplined in academic spaces. These inscriptions are social codes and norms that regulate our performances as 'good' teachers or 'reasonable' citizens. Furthermore, bodies discipline and monitor their own performances. In turn, sites of domination and resistance are produced. Hence, academic spaces are re-inscribed by these sites. New codes and norms are produced. New sites of domination and resistance are produced. In this way, space and bodies become mutually constitutive. These new understandings of space and bodies enable us to think about their relationship in new ways. 


\section{References}

Bannerji, H., Carty, L., Dehli, K., Heald, S., \& McKenna, K. (1991). Unsettling Relations: The university as a site of feminist struggles. Toronto: Women's Press.

Bartky, S. L. (1988). Foucault, Femininity and the Modernization of Patriarchal Power. In I. Diamond \& L. Quinby (Eds.), Feminism and Foucault: Reflections on resistance. Boston: Northeastern University Press.

Bartlett, A. (1998). A passionate subject: Representations of desire in feminist Pedagogy. Gender and Education, 10(1), 85-92.

Braidotti, B. (1991). Patterns of Dissonance: A study of women in contemporary philosophy. New York: Routledge.

Brook, B. (2000). Is there anybody there? In C. O'Farrell, E. McWilliams, \& D. Meadmore, Taught Bodies. York: Peter Lang.

Butler, J. (1993). Bodies that Matter: On the discursive limits of 'Sex'. New York: Routledge.

Duncan, N. (1996). BodySpace: Destabilizing geographies of gender and sexuality. New York: Routledge.

Foucault, M. (1977). Discipline and Punish: The birth of the prison. London: Allen Lane.

Foucault, M. (1985). The History of Sexuality, Vol. 2: The use of pleasure. New York: Pantheon.

Gatens, M. (1991). Corporeal Representation in/and the Body Politic. In R. Diprose \& R. Ferrell (Eds.) Cartographies: Poststructuralism and the mapping of bodies and spaces. Australia: Allen \& Unwin

Grosz, E. (1994). Volatile Bodies. Indianapolis: Indiana University Press.

Grosz, E. (1992). Bodies-Cities. In B. Colomina (Eds.) Sexuality and Space. New York: Princeton Architectural Press.

Hooks, B. (1994). Teaching to Transgress: Education as the Practice of Freedom. New York: Routledge.

Jameson, F. (1991). Postmodernism, or the Cultural Logic of Late Capitalism. London: Verso.

Keith, M. \& Pile, S. (1993). Place and the Politics of Identity. New York: Routledge.

Kirby, V. (1997). Telling Flesh: The substance of the corporeal. London: Routledge.

Massey, D. (1994). Space, Place and Gender. UK: Polity Press.

McWilliam, E. (2000). Laughing within Reason: On pleasure, women, and academic performance. In E. A. St. Pierre \& W. S, Pillow (Eds.) Working the Ruins: Feminist poststructuralist theory and methods in education. New York: Routledge.

Ng. R. (1993). Racism, Sexism, and Nation Building, in Canada. In C. McCarthy \& W. Crichlow (Eds.) Race Identity and Representation in Education. New York: Routledge

O'Farrell, C., Meadmore, D., McWilliam, E. \& Symes, C. (2000). Taught Bodies. New York: Peter Lang Publishing.

Pile, S. (1996). The Body and the City: Psychoanalysis, space and subjectivity. London: Routledge. 
Pillow, W. S., (2000). Exposed Methodology: The body as a deconstructive practice. In E. A. St. Pierre \& W. S, Pillow (Eds.) Working the Ruins: Feminist poststructuralist theory and methods in education. New York: Routledge.

Russo, M. (1994) The Female grotesque: Risk, excess and modernity. New York: Routeledge.

Simmonds, F. N. (1997) My Body, Myself: How does a black woman do sociology? In H. S. Mirza (Ed) Black British feminist criticism: a reader. London: Routledge.

Soja, E. (1989). Postmodern Geographies. London: Verso.

Spelman, E. V. (1988). Inessential Woman: Problems of exclusion in feminist thought. Boston: Beacon Press.

Spivak, G. (1990). The Post-Colonial Critic: Interviews, strategies, dialogues. New York: Routeledge.

Teather, E. K. (1999). Embodied Geographies: Space, bodies and rites of passage. London: Routeledge.

Wise, S. (1997). What are Feminist Academics For? In L. Stanley (Ed.) Knowing Feminisms. London: Sage. 